\title{
Determinants of time to first birth among women in ages I5-24 in Swaziland
}

\author{
Karabo Mhele ${ }^{1}$ \\ Population Training and Research Unit (POPUNIT), \\ North West University - Mafikeng Campus
}

\begin{abstract}
The purpose of this study was to examine factors influencing transition to first birth at ages below 20 among women in Swaziland. Study respondents were women in ages 15-24 and data was obtained from 2007 DHS. The method involved estimation of survival times for different age cohorts using Kaplan-Meir method, while Cox model was used to estimate the effect of different covariates on transition to first birth.

Nearly $42 \%$ of respondents had given birth and approximately $80 \%$ were below age 20. Overall, survival times before birth was 18.22 years. Education, age of first coitus and timing of contraception use were significantly associated with transition to first birth; on the other hand, household size, place of residence and wealth index were significant only for age cohort 15-19. The study recommends for policies to retain women in school up to secondary level of education.
\end{abstract}

Keywords: Age at first birth, adolescence, Swaziland

\section{Résumé}

Le but de cette étude était d'examiner les facteurs qui influencent la transition à la première naissance chez les femmes âgées de moins de 20 ans au Swaziland. Les participantes dans celle étude étaient des femmes âgées entre 15-24 ans et les données ont été obtenues à partir de 2007 DHS. L'analyse des données comprenait l'estimation du temps de survie pour les différents groupes d'âge en utilisant la méthode de Kaplan- Meir , alors que le modèle de Cox a été utilisé pour estimer l'effet de différentes variables sur la transition à la première naissance

Près de $42 \%$ des participantes avaient déjà donné naissance et environ $80 \%$ étaient en dessous de l'âge 20. Dans l'ensemble, le temps de survie avant de

\footnotetext{
${ }^{1}$ Correspondence:

P/Bag x2046

Mmabatho, 2735

Email: Karabo.mhele@nwu.ac.za
} 
donner naissance était de 18,22 ans. L'éducation, l'âge au premier rapport sexuel et le moment de la première utilisation de la contraception étaient significativement associés à la transition vers la première naissance ; d'autre part, la taille du ménage, le lieu de résidence et l'indice de richesse était significative seulement pour la cohorte d'âge 15-19. Cette étude recommande des politiques pour retenir les femmes à l'école jusqu'au niveau secondaire de l'éducation.

Mots-clés: âge à la première, l'adolescence, le Swaziland

\section{Introduction}

Research findings have indicated that high infant and maternal mortality rates, increased rate of school dropout and low economic status of women are linked to adolescent fertility in many countries. Finlay et al. (20ll) found that the risk of infant mortality increases with a decrease in age of woman at birth. Furthermore, maternal age was negatively associated with stunting, underweight and diarrhoea in children. In addition, Mirowsky (2005) indicated that postponing maternal age to ages above 19 reduced the risk of obstetric problems, spontaneous abortion and ectopic pregnancy to the lowest level; delaying first birth was also associated with improved economic status of women through increased labour force participation (Bratti \& Cavalli, 2013) and enhanced family income (Hague \& Sayem, 2009).

Although adolescent fertility rate in Swaziland has been declining in the past, the country experienced 78 births per 1000 adolescent women in 2010 (World Bank, 20II). This rate suggests that Swaziland had the second highest fertility rate among the five countries in southern Africa. Lesotho was the highest in the region with 90 births per 1000 adolescents while Namibia, South Africa and Botswana experienced the rates of 63,54 and 47 respectively in the same period. Surprisingly, a study by Warren et al. (1992) had found that adolescent fertility in Swaziland was almost half of the rate experienced in some of the countries in the region in 1985. This perhaps, suggests that adolescent fertility in the country had stagnated in the past when compared to some of countries in the region. Different studies have examined the effects of different socio-economic factors on adolescent pregnancy. However, there is a dearth of literature pertaining to the effects of these factors on the different age cohorts. This article looks at the impact of these factors across different age cohorts to determine whether the impact varies between these cohorts.

The purpose of this study was three fold; firstly to estimate the survival times before first birth among women in different age cohorts; secondly, to evaluate the impact of different socio-economic and demographic factors on the probability that a woman would experience a transition to first birth at ages below 20 amongst women in ages 15-24 in Swaziland and lastly, to establish whether the effects of the above covariates differ between women in different age cohorts.

Social disorganization theory seems to be the most appropriate theory to explain 
variation in the level of adolescent fertility. The theory postulates that dysfunctional behavior is likely to occur in societies where there is a diminishing authority of social institutions over the behaviour of individuals in the community. As argued by Browning (2002), the capacity of the families, schools, and other social institutions to monitor dissenting behaviour of its members is greatly reduced in societies where there is economic and social deprivation. In this study, social disorganization is conceptualised as breakdown of social norms due to diminished parental authority over young women in different households. Given that societal norms and values are transmitted through socialization within a household in which a child is born, young women from femaleled households; households with poor standard of living and households with larger sizes are more likely to experience a relatively higher adolescent fertility rate because of diminished authority in these households. Adolescents in female-headed households are likely to initiate sex at younger ages and also to engage in other forms of delinquency because of the diminished parental control in such households. Also, young women from poor households may engage in sex in exchange for gifts or money (Kaufman \& Stavros, 2004) in order to enhance their economic status; while those in larger household sizes are more likely to start childbearing at lower ages (Marteleto, 2006) because parental authority is likely to diminish with an additional member in the household. Similarly, because of gender imbalances in many societies in the developing countries, households with limited resources may discriminate against girls when allocating resources for education (Nekatibeb, 2002), meaning that girls from these households are likely to have a lower educational attainment, and this will increase the likelihood of childbearing at younger ages .

Literature points to a number of individual, school and household level factors as well as cultural dynamics that are associated with maternal age at first birth. At individual level, the level of education attained by an individual woman has the strongest effect in delaying first birth (Nahar \&Min, 2008). A study by Mahy and Gupta (2002) in different sub-Saharan countries found that educated women were less likely to have first birth before the age of 18 when compared to women with no education. The reason for this is because women, who have attained higher level of education, especially from secondary level and above, are more likely to use contraceptive methods and also have a relatively lower ideal family size (Bbaale \& Mpuga, 20I I; Bongaarts, 2010). Other findings indicated that initiating sexual activity at ages below 16 increases the risk of first birth at younger ages (Suh et al., 2007); the reason being that sex at younger ages is less likely to involve contraception (Kaufman \& Stavrou, 2004; Manzini 200I).

Birth control is one of the key proximate determinants affecting age at first birth, yet only 13\% of the sexually active adolescents in sub-Saharan Africa were using some form of birth control in the period between 1998 and 201I (UNFPA, 2013), suggesting that these women were at risk of both unintended and mistimed pregnancies. Studies have 
identified a number of factors impeding the use of birth control in different countries. A study in Swaziland revealed that contraception is associated with miscarriages and other negative outcomes (Ziyane \& Ehlers, 2006); while in South Africa young women believed that contraception affects one's ability to bear children and also increases weight of a person using it (Maholo et al., 2009). The negative perception is likely to deter many young women from using contraception, especially given that fertility is still accorded a high status in these countries.

School performance is also associated with maternal age at first birth. Girls who were enrolled in a relatively lower school grade at age 14 due to temporary school withdrawal or grade repetition are more likely to become pregnant before the age 20 when compared to those who were in advanced grade at this age (Marteleto et al., 2008; Mhele \& Ayiga, 2013). Other studies found that factors at household level play a critical role in determining a woman's age at first birth. Women who reside in larger households tend to initiate family formation earlier than women coming from households with smaller sizes (Marteleto 2006; Grant \& Hallman, 2006). Children in larger households possibly receive less attention and supervision from their parents (or heads) than those coming from households with smaller sizes. In addition, Zwang \& Garene (2008) found that adolescents in households with absent fathers are more likely to lack parental authority. It is possible that they will engage in sexual activity at relatively younger ages and as a result, get exposed to the risk of teenage pregnancy. Like households with bigger sizes, young women from households with absent fathers are more likely to lack parental control than those in two-parent households will receive, and are therefore inclined to get involved in behaviour that is detrimental to their future.

Cultural dynamics have a direct influence on the timing of transition to marriage and motherhood. In societies with strong cultural association, childbearing is often a conscious effort by an individual woman to enhance her status in a society because a woman who cannot bear children is seen as handicapped and often carries an inferior status in a society (Ziyane et al., 2003). Consequently, women in such cultural settings are likely to commence childbearing at the earliest possible time in order to maximise the chances of having many children. Moreover, birth is an indication that a woman is fertile; something that is likely to attract a potential marriage partner and therefore, desirable in the eyes of many women. Again, sexually active women who want to delay childbearing are expected to get approval from their partners before using contraception (Ziyane \& Ehlers, 2006); however, young women are generally afraid to discuss sexual matters with their partners for fear of losing these partners (Kaufman \& Stavrou, 2004). The social environment where young people grow up has an influence on sexual behaviour of the individual women which might affect the timing of transition to motherhood. This in turn is influenced by the social institution and role models in a particular community (Teitler \& Weiss, 2000). The occurrences of childbearing at ages below the age of 20 is likely to be lower in communities where adolescent 
childbearing is socially sanctioned than otherwise.

\section{Data and methods}

The study used data from the 2006/7 Swaziland Demographic and Health Survey based on a national representative sample of women in reproductive age group. A sample of 2320 women in ages 15-24 was used to achieve the objectives of the study. In order to ensure representation across the country and to correct for nonresponses in the survey, the data was weighted taking into consideration the complex survey design using the "svyset" command in Stata. Demographic and Health Survey data is suitable for this purpose because it comprises of variables pertaining to age at which respondents had first birth. Besides, other background information such as age at time of the interview; level of school attained by an individual woman; age of sexual debut; timing of the use of contraception in relation to first birth, religion/denomination, household information such as wealth index and household size is available.

Data analysis involved the use of used Kaplan-Meier method to estimate the proportion of women surviving at ages below 20 before experiencing the event of first birth. Furthermore, bivariate analysis was used to estimate the differentials in mean survival times by different covariates in the study. Lastly, Cox proportional hazards model was applied at multivariate level in order to estimate the effects of different variables on the risk of first birth while controlling for the effects of other background variables. The latter method is deemed appropriate for this particular study because it can accommodate censored cases, implying that even women who had not had first birth at the time of the interview contributed in the estimation of the survival time. Data was analysed using Stata version II to estimate the survival times and hazard rates, while SPSS version 16 was used to estimate the mean survival times for different covariates.

As stated before, the multivariate analysis in this paper used Cox proportional hazards model; the model assumes that the hazard rate of the different explanatory variables in the model is "proportional" at all points in the period under analysis. The covariates whose values change over time are said to violate this principle and therefore are at risk of either over-estimating or underestimate the true value of the covariate at different points. The model was evaluated using the "estat phtest" command in Stata. In essence, this exercise was meant to test for non-zero slope in a generalised linear regression of the scaled Schoenfeld residuals on time. The results of this model evaluation showed that only one variable; 'age at sexual debut' was significantly interacting with time in the model and therefore, had a non-zero slope. This suggests that this variable should be interpreted with caution as it might either over-estimate or underestimate the hazard rate at different periods of survival time.

\section{Measures in the study}

The dependent variable in the study is the number of years that elapsed at ages below 20 before a woman experienced first birth. The beginning of exposure time was 
measured from the date of birth of the respondent until the time of first birth. In cases where the respondent had not experienced first birth at time of the interview and was younger than 20 years, the age of the individual was used as an indicator of survival time. An individual who experienced first birth at ages below 20 was coded "I" and " 0 " for those who did not give birth at ages below 20, irrespective of whether that individual had not given birth at all or had postponed it to later ages.

Predictor variables in the study included age cohorts 15-19 and 20-24; the level of education categorised as less than primary (reference category), completed primary, incomplete secondary and secondary or higher level of education. The dummy variable for contraceptive use was coded as "I" when a woman started using contraceptive method before first birth; " 2 " when contraception was used only after birth and " 3 " for those who never used any form of contraception. Furthermore, the dummy for age at sexual debut reflected age which a woman survived to before her first coitus and the variable was categorised as "ages below 15 " for those who had sex at ages below 15 and $15,16,17$ and above 17 for women who have reached the respective ages without having initiated sexual intercourse. For example, age 16 indicates that a woman was 16 years at a time she experienced first sexual intercourse, or that she was 16 years at time of interview and had not yet experienced first coitus. Women in this age group would not have experienced sexual intercourse at an earlier age.

Marital status had three categories showing the status of a woman at a time when she experienced birth of her first child. In addition to "never married" women, those who were married were divided further into two sub-categories showing the timing of first birth in relation to marriage. The variable therefore was "married, before first birth" and "married, after first birth". The reason for separating those who were married into two categories was to determine whether marital status at time of birth had any influence on the age at which a woman would give first birth.

Another variable included in the model was religion categorised as "Zion" "Charismatic", "Protestant", "and "others". Furthermore, the level of wealth in the household (wealth index) in which the respondent was residing was recoded into three dummy variables which were "poor" "middle" and "rich" in the wealth index. Moreover, the dummy for the sex of the head of the household was categorised as "I" for male and " 0 " for female-headed households, while the different household sizes were grouped according to following categories: "I-4" "5-6" "7-8" and sizes above 8.

Region and place of residence were also included in the model as contextual factors. The rational for including region separately is because it is a proxy for cultural context in which transition to motherhood is likely to occur. The different regions were Hhohho, Manzini, Shiselweni and Lubombo. In case of place of residence, the urban place of residence had two categories to differentiate between respondents living in a city and those living in a town, in addition to rural place of residence. 


\section{Results}

Table I presents the distribution of different individual, household and other background variables in the study. The results in this table indicate that $42 \%$ had given birth and more than $80 \%$ were in ages below 20 at time of first birth. Distribution of the ages at first birth indicated that slightly more than a quarter $(25.7 \%)$ of those who had given birth were 16 years or below at time they had first birth, while $22.1,16.7 \%$ and $15.3 \%$ were 17,18 and 19 years respectively and only $20.1 \%$ were in ages above 19.

Majority of the study respondents $(55 \%)$ were in 15-19 age cohorts, while women in 20-24 age cohorts accounted for the remaining $45 \%$ of the sample. Furthermore, $26 \%$ had attained education level lower than primary while $1 \mathrm{I} .5 \%$ and slightly less than a half (48\%) had primary and some secondary levels of education respectively. Only $14.6 \%$ had completed secondary or higher level of education. Whereas nearly $7 \%$ of the sample had had sexual debut at ages below 15, 18.2\%, $21.7 \%$ and $18.8 \%$ respectively reached age 15,16 and 17 before initiating sexual intercourse and more than one-third (34.9\%) were above 17 years. Significant majority $(83.2 \%)$ of these respondents were never married; $8 \%$ were married and had first birth within marriage, while $8.8 \%$ were married after having the first birth. With regard to religion, slightly more than one-third $(37 \%)$ of the respondents were members of the Zion church, while $18 \%$ and $24.8 \%$ attended Charismatic and Protestant respectively while $19.9 \%$ were members of "other" denominations or religious groups. The results further indicate that $21 \%$ used contraception before first birth, while $29 \%$ used contraception only after giving birth and nearly half $(49.5 \%)$ never used any form of contraception.

Table I: Distribution of respondents using weighted data

\begin{tabular}{lll}
\hline Covariate & $\%$ & Frequency \\
\hline
\end{tabular}

Ever given birth

Yes

42.1

977

No

57.9

1343

Age at first birth

\section{Less than 15}

15

16

17

18

19

$>19$
4.3

7.5

13.9

21.1

16.7

15.3

20.1

54.9.
43

73

136

216

163

149

197

Age Cohort

15-19

54.9

1274 
African Population Studies Vol. 29, No. 2, Supplement, 2015

\begin{tabular}{l}
\hline Covariate \\
\hline $20-24$ \\
Marital status
\end{tabular}

Never married

Married, before birth

83.15

Frequency

Married, after

8.02

8.83

1046

45.1

1864

178

196

Educational Attainment

Less than primary

25.6

594

Completed primary

11.5

266

Some secondary

48.3

Secondary or higher

14.6

1120

339

Age at sexual debut

Less than 15

6.5

151

15

18.2

422

16

21.6

502

17

18.7

435

$>17$

34.9

808

Contraception used

Before birth

21.1

489

After birth

29.3

678

Never used

49.6

II47

Religion/denomination

Zion

37.1

861

Charismatic

18.1

421

Protestant

24.8

Other

19.9

575

276

Household size

I-4

24.4

566

5-6

22.7

526

7-8

19.8

460

9 and above

33.1

768

Sex of the head of $\mathrm{HH}$

Male

44.1

1022

Female

55.9

1297 


\begin{tabular}{lcc}
\hline Covariate & $\%$ & Frequency \\
\hline Wealth Index & 34.2 & \\
Poor & 19.9 & 793 \\
Middle & 45.9 & 462 \\
Rich & & 1065 \\
& & \\
Place of residence & 12.1 & 280 \\
Large city & 11.3 & 263 \\
Town & 76.6 & 1776 \\
Rural & & \\
Region of residence & 24.7 & 574 \\
Hhohho & 33.6 & 780 \\
Manzini & 22.4 & 520 \\
Shiselweni & 19.2 & 446 \\
Lubombo & 100 & 2320 \\
Total & 100
\end{tabular}

Close to a quarter $(24.4 \%)$ of women in the study were residing in a household with less than 5 members, while 23\%, $20 \%$ and $33 \%$ were respectively coming from households with 5-6, 7-8 and 9 and above members. This means that more than $50 \%$ of the respondents came from households with 7 or more members.

On the other hand, respondents from female-headed households contributed $56 \%$ of the study respondents, while $44 \%$ were from households headed by males. Slightly more than one-third $(34.2 \%)$ of these women came from households classified as "poor" in the wealth index, while $19.9 \%$ and $45.9 \%$ were respectively from "middle" and "rich" households. Significant majority (76.6\%) of these women were residing in the rural place of residence, while $11.3 \%$ and only $12 \%$ were respectively were from town and large city. The results indicate also that $24.7 \%, 22.4 \%$ and $19.2 \%$ of the respondents came from Hhohho, Shiselweni and Lubombo respectively, while Manzini contributed $33.4 \%$ of the study sample.

Figure I presents Kaplan Meier estimates showing proportion of women surviving before first birth at ages below 20 for women in different age cohorts. For each age (in years), the study estimated the conditional probability that a woman would survive to the end of that age without having experienced first birth provided that she did not experience the event before that. Survivor function for age cohort 15-19 lies above that of 20-24 age cohorts at all points in the survival period and the results were statistically significant $(p<0.000 \mathrm{I})$. Nearly three-quarters $(7 \mathrm{I} \%)$ and $64 \%$ of women in age cohort 15-19 
reached ages 18 and 19 respectively before likely to postpone first birth to relatively first birth compared to $61 \%$ and $48 \%$ in higher ages compared to their age cohort 20-24. This indicates that counterparts in age cohort 20-24.

women in younger age cohorts were more

Fig.1: Survivor function before first birth by different age cohorts

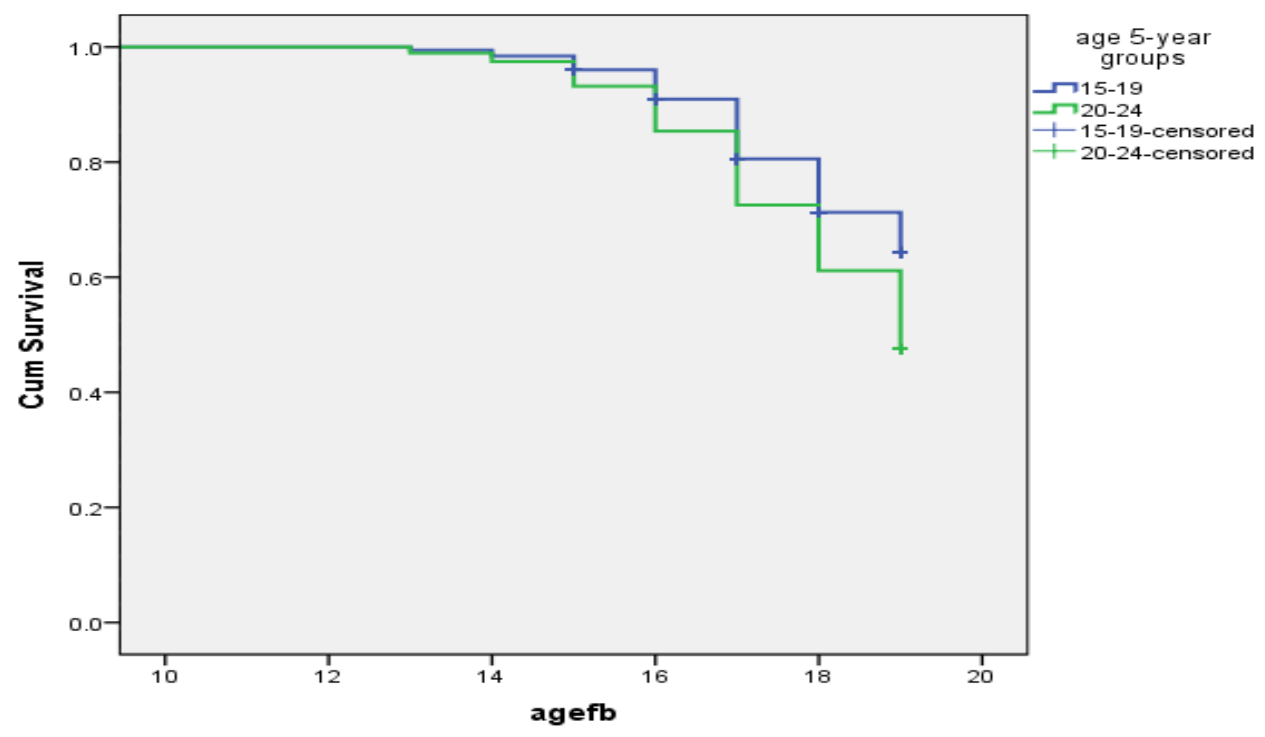

Table 2 presents differentials in mean age average of 18.37 years compared to 18.09 or survival times before first birth by years for the 20-24 age cohort $(p<0.005)$. different background factors. The The survival times were positively and estimated average age at first birth for the significantly associated with the level of entire study sample was 18.22 years; education $(p<0.0001)$. For example, having however, the results showed that the mean a secondary or higher level of education age at first birth varied considerably with increased the age of first birth by more than different background factors. Age cohorts 1.63 years compared to someone with less 15-19 had higher survival times with an than primary level of education. 
African Population Studies Vol. 29, No. 2, Supplement, 2015

Table 2:Mean survival times by different covariates

\begin{tabular}{|c|c|c|c|}
\hline Covariate & $\begin{array}{l}\text { Mean } \\
\text { time }\end{array}$ & survival & $\begin{array}{c}\text { Log-rank test } \\
x^{2}\end{array}$ \\
\hline
\end{tabular}

Age Cohort

15-19

18.37

$33.34 * * *$

20-24

18.09

Educ. level

Less than primary

17.76

$190.35 * * *$

Primary

18.02

Incomplete Sec.

18.34

Secondary

18.79

Age at sexual debut

Less than 15

16.38

$192 * * *$

15

16

17.4

17.7

17

18.3

$>17$

18.7

Contr. use

Before birth

18.63

190.34***

After birth

17.40

Never used

18.92

Religion

Zion

17.97

$83.72 * * *$

Charismatic

18.42

Protestant

18.30

Other

18.22

\section{Marital status}

Never married

17.80

$339.7 * * *$

Married, before birth

18.40

Married, after birth

16.92

Household size

I-4

18.19

$32.9 * * *$

5-6

18.35

7-8

18.36

9 and above

18.07 


\begin{tabular}{lcc}
\hline Covariate & $\begin{array}{l}\text { Mean } \\
\text { time }\end{array}$ & $\begin{array}{c}\text { Log-rank t } \\
x^{2}\end{array}$ \\
\hline $\begin{array}{l}\text { Sex of the head } \\
\text { Male }\end{array}$ & 18.11 & $25^{* *}$ \\
Female & 18.30 & \\
Wealth Index & & $50.02^{* * *}$ \\
Poor & 18.03 & \\
Middle & 18.20 & $20.63^{* *}$ \\
Rich & 18.34 & \\
Place of residence & & \\
Large city & 18.45 & $25.11^{* * * *}$ \\
Town & 18.13 & \\
Rural & 18.20 & \\
Region of residence & & \\
Hhohho & 18.1 & \\
Manzini & 18.38 & \\
Shiselweni & 18.34 & \\
Lubombo & 18.02 &
\end{tabular}

\section{Total}

$* \mathrm{P}<0.05$ *** $\mathrm{p}<0.005$ *** $\mathrm{p}<0.000$ I

The results further indicate that the mean age at first birth increased significantly $(p<0.000 \mathrm{l})$ when age of first coitus is deferred to an older age. Compared to women who initiated sex at ages below 15, those who reached age 15 before sexual debut had survival times increased by one year from 16.4 to 17.4 years while it increased by two years or more among those who reached age 17 and ages above 17 respectively without having had sexual intercourse.

The timing of contraceptive use in relation to first birth was a significant predictor of the number of years survived before first birth. Women who used contraception prior to first birth survived to an average of 18.6 years compared to I7.4 years for those who used a method only after experiencing first birth $(p<0.00 \mathrm{I})$; this suggest that sexually active women who used contraceptive method before birth increased survival times by more than one year. On the other hand, those who had never used any method had survived to almost 19 years. The plausible explanation for a relatively higher mean in the latter group is because majority in this group were not sexually active, and therefore did not have reason to use contraceptive method. While the mean number of years varied significantly $(p<0.005)$ according to one's religious membership, the differences between the 
members of the different religious groups were only 0.45 years. Members of the Zion church had the lowest average survival time at 17.97 years while members of the Protestants and Charismatic had the highest survival times at 18.30 and 18.42 years respectively.

The size of the household was also significantly and negatively associated with age at first birth, even though household sizes larger than 8 were an exception in this case. Households headed by males had lower mean survival times with an average of 18.11 years compared to 18.30 for female-headed households. As expected, women who came from households with wealth index classified as "rich" had the longest duration to first birth with a mean of $\mathbf{8 . 7 4}$ years compared to 18.03 years for those coming from "poor" households. With regard to place of residence, the mean was highest amongst women residing in the larger city (18.45 years) followed by rural area (18.20 years) and lowest survival times were observed among those residing in town (18.13 years); women in Shiselweni and Manzini regions postponed first birth to 18.38 and 18.34 years respectively, while those in Hhohho and Lubombo experienced first birth at relatively earlier ages which were 18.01 and 18.02 years.

\section{Multivariate analysis}

The purpose of this section was to estimate the relative risk, or the hazard ratio $(\mathrm{HR})$ of experiencing first birth at ages below 20 for different age cohorts while controlling for the effects of other background variables. Even though almost all variables were significant at bivariate level, the results in Table 3 showed that the level of educational; age of sexual debut; timing of contraception use in relation to first birth; household size and place of residence remained significant after controlling for the effects of other background variables.

Education had a negative effect on age at first birth; however, this variable was significant only at levels above primary level of education. Women in age cohorts I5-19 who had attained some secondary education were $33 \%(p<0.05)$ less likely to have experienced first birth; the hazard rate was further reduced by $72 \%(p<0.05)$ among those with secondary level and levels of education above secondary. Among women in 20-24 age cohorts, the hazard rate was reduced by $47 \%$ $(p<0.005)$ for women who had attained secondary education or higher. The results were highly significant for women with levels of education above primary in the combined group where the relative risk decreased by $27 \%$ and $52 \%(p<0.005)$ respectively for women with some secondary and secondary educational level.

Age of sexual debut was a significant predictor of childbearing at ages below 20 for both age cohorts. The risk among women in 15-19 age cohorts was reduced by $65 \%, 74 \%$ and $85 \%$ for women who initiated sex at ages 15,16 and 17 respectively; and it was reduced by $39 \%$, $48 \%$ and $63 \%$ among women in the older age cohort. In the total sample, the risk was reduced by $52 \%, 61 \%$ and $74 \%$ for age 15,16 and 17 respectively and further by $89 \%$ for those who postponed sexual act to ages above $17(\mathrm{p}<0.005)$.

Using a contraceptive method only after birth increased the relative risk for both age cohorts. The risk increased by nearly six and five times more in age 
cohorts 15-19 and 20-24 respectively. Women who had first birth and married later had higher relative risk; however, the variable was only significant among women in 20-24 age cohorts where the risk was $67 \%$ higher than women who had never married.

Belonging to some religion was not statistically associated with first birth at ages below 20 among women in both age cohorts. Residing in households with 7-8 and 9 or more members significantly increased the hazard rate by $73 \%$ $(p<0.01)$ and $87 \%(p<0.005)$ respectively among women in the younger age cohort; however, the rate increased by $29 \%$ and $26 \%$ respectively in the combined sample among women in these households. While the dummy for the sex of the head of the household was not significant, wealth index was significant only among women in 2024 age cohorts where the risk increased by $23 \%$ for those coming from households classified as "rich" in the wealth index.

The dummy for place of residence showed that women in age cohort I5-19 who were residing in town were three times more likely to have experienced birth during adolescence $(p<0.005)$ and the risk increased by $50 \%$ when both age cohorts were combined $(p<0.05)$. Surprisingly, the dummy for rural residence was only significant $(p<0.05)$ in the combined group.

Table 3: Predictors of time to first birth among different cohorts of women

Variables

\begin{tabular}{llllll} 
15-19 & \multicolumn{3}{c}{$20-24$} & \multicolumn{2}{c}{ ALL } \\
\hline Hazard & Std. & Hazard & Std. Hazard & Std. err $95 \% c i$ \\
Ratio & err. & Ratio & err. & Ratio & \\
\hline
\end{tabular}

\section{Education}

Less than prim. $\quad 1.00$

Completed $\quad 1.08$

primary

$0.67^{*}$

0.20

1.00

1.00

Some secondary $\quad 0.28 *$

0.10

1.07

0.14

0.99

0.10

$0.81-1.23$

Secondary +

0.14

0.83

0.09

0.73 ****

0.07

$0.60-0.88$

Sexual debut

$<15$ years

1.00

15

$0.35^{* * * *}$

0.07

0.53 ***

0.09

0.48***

0.08

$0.34-0.67$

16

0.26 ***

0.05

1.00

1.00

17

$0.15^{* * * *}$

0.03

0.61 *

0.11

$0.48^{* * * *}$

0.08

0.35-0.65

$0.52 * * *$

0.09

$0.39 * * *$

0.06

$0.29-0.52$

$>17$

$0.04^{* * * *}$

0.01

0.37 ****

0.07

0.26 ****

0.04

$0.18-0.35$

0.16 *** 0.03

0.1 I****

0.02

$0.08-0.15$

Contr. use

Before birth

After birth

1.00

Never used

$5.79 * * *$

1.00

1.00

0.65

1.22

4.88***

$0.87 \quad 4.4^{* * * *}$

0.53

3.44-5.55

$\begin{array}{llll}0.15 & 1.50 & 0.31 & 0.77\end{array}$

0.12

$0.56-1.03$

Marital status 
African Population Studies Vol. 29, No. 2, Supplement, 2015

Variables

\begin{tabular}{llllll} 
15-19 & \multicolumn{2}{c}{$20-24$} & \multicolumn{2}{c}{ ALL } \\
\hline Hazard & Std. & Hazard & Std. & Hazard & Std. err \\
Ratio & err. & Ratio & err. & Ratio & \\
\hline
\end{tabular}

$\begin{array}{llll}\text { Never married } & 1.00 & 1.00 & 1.00\end{array}$

Married, before 0.70

$0.14 \quad 1.21$

$0.14 \quad 1.02$

$0.11 \quad 0.83-1.25$

birth

Married, after $\mathbf{I . 5 3}$

$0.38 \quad 1.67^{* * * *} \quad 0.21$

I. $49 * * *$

$0.17 \quad 1.18-1.86$

birth

Religion

Zion

1.00

1.00

1.00

Charismatic

1.05

$0.19 \quad 0.84$

0.10

0.91

0.10

$0.73-1.13$

Protestant

0.82

0.18

0.89

0.10

0.92

0.09

$0.75-1.12$

Other

1.06

$0.20 \quad 0.85$

$0.08 \quad 0.86$

0.08

$0.72-1.03$

Household size

I-4

1.00

1.00

$\begin{array}{ll}0.27 & 0.97\end{array}$

$0.14 \quad 1.02$

5-6

I. 10

0.40

1.18

$0.17 \quad 1.29 *$

$0.13 \quad 0.80-1.30$

7-8

I. $87^{* * *}$

0.4 I

0.12

I.26*

$0.16 \quad 1.01-1.64$

9 and above

Sex of the head

Male

1.00

1.00

1.00

Female

1.04

0.13

0.94

0.07

0.94

$0.06 \quad 0.83-1.07$

Wealth Index

1.00

1.00

1.00

Poor

0.76

$0.14 \quad 1.05$

0.12

0.98

$0.10 \quad 0.80-1.18$

Middle

0.98

$0.17 \quad 1.23 *$

$0.23 \quad 1.20$

0.11

$0.99-1.44$

Rich

\section{Residence}

Large city

1.00

1.00

1.00

Town

3.23****

I.II 1.27

0.22

I.50***

$0.20 \quad I .14-1.96$

Rural

1.83

0.58

1.28

0.18

I.33*

$0.16 \quad 1.04-1.67$

Region

Hhohho

$1.00 \quad 1.00$

1.00
0.84

1.00

Manzini

0.93

0.18

0.10

$0.83 *$

$0.08 \quad 0.69-0.99$

Shiselweni

0.97

$0.19 \quad 0.85$

0.11

0.83

$0.08 \quad 0.67-1.01$

Lubombo

0.89

$0.15 \quad 0.94$

0.13

0.89

$0.09 \quad 0.72-1.09$

* $\mathrm{p}<0.05$ *** $\mathrm{p}<0.01$ **** $\mathrm{p}<0.005$

The dummy variable for the region indicated that none of the regions with an exception of Manzini were significantly different from Hhohho region. Women 
who came from Manzini region were 17\% less likely to experience the event than those in Hhohho region.

In conclusion, the results of multivariate analysis indicated that the risk of birth at adolescent ages significantly decreased with an increase in the level of education and age of sexual debut; it also increased with household sizes and when birth control was deferred to period after birth, and among women residing in both town and rural place of residence

\section{Discussion}

Age at first birth has implication for different social and economic outcomes in the lives of women such as an increased infant and maternal mortality levels and school dropout rate. The objectives of this study was to estimate the survival times before first birth and also to determine the impact of different socio-economic and demographic factors on the relative risk that a woman will have first birth at ages below 20 among respondents in ages I524. The results indicated that age of first birth is increasing among recent birth cohorts thus confirming that adolescent fertility is declining in Swaziland, as it is the case in other developing countries (UNFPA, 20I3).

The results further indicated that $37 \%$ of the study respondents had attained primary, or levels of education lower than primary suggesting that there is a need to improve education among women in Swaziland. While different studies have found that increased level of education is positively associated with age of first birth (Bongaarts, 2010; Nahar \& Min, 2008), this study showed that the benefit of education in delaying first birth becomes significant only at secondary or levels of education above secondary. The reasons for this is because higher level of education induces women to have a lower ideal family sizes (Bongaarts, 2010), which in turn increases contraceptive prevalence rate (Bbaale \& Mpuga, 20II). The motivation for postponing birth to advanced ages for women with higher levels of education might be because the opportunity cost of childbearing increases at higher levels of education. For example, women who start childbearing at lower ages may drop from school after birth and consequently, forgo the opportunity of being employed in better paying jobs that comes with higher educational attainment.

Nearly $40 \%$ of the respondents who were sexually active initiated sexual intercourse at age 17 or below (not shown). Results in this study confirmed that early sexual debut increases the likelihood of having birth at comparatively younger ages (Suh et al., 2007). Ziyane et al. (2006) found that young people in Swaziland are habitually under pressure to bear children in order to expand the family and this pressure is likely to lead to sexual initiation at fairly younger ages. While many women initiated sexual activity at younger ages, some started using contraception only after having the first child. Swaziland is not an exception in this case, as contraceptive prevalence rate is low in many countries in sub-Saharan Africa (UNFPA, 20I3); hence many women are predisposed to the risk of unintended birth in these countries. The study results indicated that using contraception only after birth increased the risk by more than four times compared to women who 
started using some method before birth. This implies that many unwanted births could have been prevented by using contraceptive method at the onset of sexual activity. Contraceptive use has a potential not only to postpone unwanted births, but also to reduce both infant and maternal mortality rates by averting pregnancies among women who are at higher risk of these events (Mirowsky, 2005). Moreover, young girls do not insist on condom use during sex for fear of offending their partners, especially if they (girls) want the relationship to continue (Kaufman \& Stavrou, 2004). In some cases, a girl may avoid using contraception in order to prove her fertility to the prospective husband (Ziyane \& Ehlers, 2006). Also, the status of women in society becomes an impediment for contraceptive use. For example, in Swaziland a woman has to seek approval from her partner before she can use a birth control (Ziyane \& Ehlers, 2006). Moreover, in cases where sexual activity at younger ages is not permissible, young girls may be reluctant to access family planning services because that will be an indication that they are sexually active.

A household as a primary agent of socialization plays a critical role in shaping behaviour of children residing in that household and therefore, the risk of adolescent fertility is likely to differ within different types of households. Young women coming from larger households are likely to start family formation earlier compared to those coming from relatively smaller households (Materelelo 2006; Grant \& Hallman, 2006). This study confirmed that staying in a household with sizes larger than six increased the relative risk of transition to motherhood at ages below 20. This could be attributed to diminished control or an inadequate individual attention and guidance for young girls in these households. This problem is expected to continue in Swaziland as more than half $(52 \%)$ of the respondents came from households with sizes larger than six.

Surprisingly, the findings revealed that women who were residing in town were significantly more likely to have started motherhood at young ages compared to those residing in large city. On the other hand, women who were residing in rural areas were not statistically different from those coming from the city. Brewster et al. (1993) argued that different communities would presents varying opportunity costs of early childbearing to women residing in the communities. Given that rural areas are normally disadvantaged in many aspects, one would have expected that the rate of transition to motherhood would be higher in the rural areas.

\section{Conclusion}

In conclusion, the study found that the level of education at secondary level and above, age of sexual debut and the timing of contraceptive use in relation to first birth were key individual level factors associated with transition to motherhood at ages below 20. Household size and wealth index were found to be important for women at younger age cohorts, and so was residing in town. The study therefore recommends that family planning awareness programmes should be expanded to include young girls and boys before they are sexually active. While education is important for deferring age at first birth, the results indicate that it 
becomes effective at secondary and higher level of education. It is therefore recommended that policy makers should develop programs that will retain girls in school up to, and beyond secondary level. Also, cultural and other socio-economic factors that devalue the status of women in a society should be addressed at policy level in order to empower women to make reproductive decisions that are likely to benefit them.

\section{Acknowledgement}

The author is thankful to Macro International (USA) for DHS data that was used in the study.

\section{References}

Bbaale, E., \& Mpuga, P. 20II. Female Education, Contraceptive Use, and Fertility Consilience. The Journal of Sustainable Development, 6(I): 20-47.

Bongaarts, J. 2010. Poverty, Gender, and

Youth. The Causes of Educational

Differences in Fertility in sub-Saharan

Africa. Working Paper No. 20.

Population Council.

Bongaarts, J. \& Casterline, J. 20I2. Fertility

Transition: Is sub-Saharan Africa

Different? Population and Development

Review, 38 (Supplement) 153-168.

Bratti, M. \& Cavalli, L. 2013. Delayed First

Birth and New Mothers' Labor Market

Outcomes: Evidence from Biological Fertility Shocks. IZA Discussion Paper No. 7I 35 January.

Brewster, K.L., Billy, J.O.G. \& Grady, W.R. 1993. Social Context and Adolescent Behaviour: The Impact of Community on the Transition to Sexual Activity. Social Forces, 7I (3): 7I3-740.
Browning, C. R. 2002. The Span of Collective Efficacy: Extending Social Disorganization Theory to Partner Violence. Journal of Marriage and Family, 64: 833-850. doi: I0.1 I I I/j. I74 I-3737.2002.00833.x

Finlay, J.E., Ốzantin, E. \& Canning, D. 201 I . The association of maternal age with infant mortality, child anthropometric failure, diarrhoea and anaemia for the first births: evidence from 55 low- and middle-income countries. BMJ Open 20I I; I:2 e000226 doi: I 0. I | 36/bmjopen-20 I I-000226

Grant, M. \& Hallman, K. 2006. Pregnancyrelated School Dropout and Prior School Performance in KwaZulu-Natal, South Africa. Studies in Family Planning, 39(4): 369-382.

Hague, A. \& Sayem, A.M. 2009. Socioeconomic Determinants of Age at First Birth in Rural Areas of Bangladesh. Asia Pacific Journal of Public Health, 2I(I): 104-III. doi:

10.1।77//010539508329207.

Kaufman, C.E. \& Stavros, S.E. 2004. Bus Fare Please': The Economics of Sex and Gifts among Young People in Urban South Africa. Culture, Health \& Sexuality, 6(5): 377-39I.

Kumar, G.A. \& Danabalan, M. 2006. Determinants of Delayed First Birth. Indian Journal of Community Medicine Vol. 3I, (4): October-December, (4):272-273.

Maholo, R.B., Maja, T.M.M. \& Wright, S.C.D. 2009. Relationships, Perceptions and the Socio-Cultural Environment of Pregnant Teenagers in Soshanguve Secondary Schools. Africa Journal of Nursing and Midwifery, I I (2): 48-60. 
Mahy, M. \& Gupta, N. 2002. Trends and Differentials in

Adolescent

Reproductive Behavior in Sub-Saharan Africa. DHS Analytical Studies No. 3. Orc Macro. Calverton Maryland, USA. Marteleto L, Lam D., \& Ranchhod V., 2006. Schooling and early childbearing in South Africa. PSC Research Report 06610

Manzini, N. 200I. Sexual Initiation and Childbearing among Adolescent Girls in KwaZulu Natal, South Africa. Reproductive Health Matters, 9(17): 44-52.

Marteleto, L., Lam, D. \& Rachold, V. 2008. Sexual Behavior, Pregnancy, and Schooling among Young People in Urban South Africa. Studies in Family Planning, 39(4): 35I-368.

Mfono, Z. 1998. Teenage Contraceptive Needs in Urab South Africa: A Case Study. International Family Planning Perspectives, 24(4): 180-183.

Mhele, K. \& Natal, A. 2013. Factors influencing the high dropout rate of the girl child from education in South Africa: A Case study of black women in NorthWest province, South Africa. Journal of Social Development in Africa, 28(I): III-138.

Mirowsky, J. 2005. Age at First Birth, Health, and Mortality. Journal of Health and Social Behavior, 46, (March): 3250.

Nahar, Q. \& Min, H. 2008. Trends and Determinants of Adolescent Childbearing in Bangladesh. DHS Working Papers No. 48, USAID.

Nekatibeb, T. 2002. Low Participation of Female Students in Primary Education: A Case Study of Dropouts from Amhara and Oromia Regional Sates in Ethopia. Addis Ababa: UNESCO.

Suh, S., Suh, J. \& Houston, I. 2007. Predictors of Categorical At-Risk High School Dropouts. Journal of Counseling and Development, 85(2): 196-203.

Teitler, J. \& Weiss, C. 2000. Effects of Neighborhood and School Environment on Transition to First Sexual Intercourse. Sociology of Education, 73(2): 122-132.

UNFPA 2013. Adolescent Pregnancy. A Review of the Evidence. New York Warren, C.W., Johnson, J.T., Gule, G., Hlophe, E. \& Kraushaar, D. 1992. The Determinants of Fertility in Swaziland. Population Studies: A Journal of Demography, 46:I, 5-17.

World Bank. 20I I. Births per 1000 women ages 15-19. Available from http://data.worldbank.org/indicator/SP. ADO.TFRT. (Accesssed I5/09/20I5)

Ziyane \& Ehlers V. 2006. Swazi youths' attitude and perception concerning adolescent pregnancy and contraception. Health SA Gesondheid. Vol. I I No. I: 31-42

Ziyane, I. Ehlers V.J., \& King L.J. 2003. Socio-cultural deterrents to family planning practices among Swazi women. Curationis. Dec; 26(4):39-50.

Zwang J. \& Garenne M. 2008. Social Context of Premarital Fertility in Rural South - Africa. African Journal of Reproductive Health. Vol. 12, No. 2 (Aug) 98-I IO. 